\title{
O ESPAÇO/LUGAR DA ATIVIDADE DOCENTE E AS TRAMAS QUE ENVOLVEM O COTIDIANO DA SALA DE AULA
}

\author{
Neide Cavalcante Guedes'
}

\section{RESUMO}

O texto faz uma discussão sobre o cotidiano da sala de aula do professor universitário, e tem como objetivo investigar como a prática dos docentes da Universidade Federal do Piauí no Curso de pedagogia se manifesta nesse cotidiano, a partir da relação ensinar e aprender. O aparato teórico tem base em Certeau (2008), Catani et al. (2005), Maseto e Abreu (1999), dentre outros. Do ponto de vista metodológico, o estudo se baseia no dispositivo de mediação denominado de "observação colaborativa" que, de acordo com Paiva (2002) e Ibiapina (2005) pode ser definida como um recurso capaz de valorizar a participação e colaboração que culminam no processo de reflexão crítica, como princípios formativos, se potencializando a partir das etapas de descrição, informação, confronto e reconstrução de teorias e práticas inerentes ao processo ensinoaprendizagem. Com base nas observações realizadas nas salas de aula de 06 (seis) professores do ensino superior foi possível identificar como eles estabelecem a relação entre os conceitos de Ensino, Aprendizagem e Docência considerados fundamentais ao exercício da docência, e sua prática cotidiana, ou seja, como se interconectam os estudos teóricos ao cotidiano da sala de aula. Os achados evidenciam que a forma como o professor conduz a sua prática é fundamental para que o aluno possa assumir sua autonomia no que diz respeito a construção do conhecimento cientifico sistematizado, pois é o seu fazer neste cotidiano que vai determinar o grau de envolvimento nesta trama.

Palavras-chave: Sala de Aula. Professor. Observação Colaborativa.

\section{THE SPACE/PLACE OF ACTIVITY OF PROFESSOR AND THE PLOTS WHICH INVOLVE THE DAILY BASIS ACTIVITIES IN THE CLASSROOM}

\section{ABSTRACT}

This text brings about a discussion on the daily basis activities of professors in the classroom and has as an objective to investigate how their teaching practice is in the Pedagogy Course at the Federal University of Piauí from a teaching/learning perspective. The theoretical apparatus is based on Certeau (2008), Catani et al. (2005), Maseto and Abreu (1999), among others. From the methodological view, the study is based on the mediation device known as "collaborative observation" which, according to Paiva (2002) and Ibiapina (2005) can be defined as a resource

\footnotetext{
1 Pós-doutora em Educação. Professora do Programa de Pós-graduação em Educação. Universidade Federal do Piauí, Teresina/PI. E-mail: neidecguedes@hotmail.com
} 
capable of enhancing the participation and collaboration which culminate in the process of critical reflection as formative principles, if powering from the steps of description, information, comparison and reconstruction of theories and practices inherent in the teaching-learning process. Based on observations of 06 (six) university professor's performance, it was possible to identify how they establish the relationship between the concepts of Teaching, Learning and the teaching profession considered as fundamental to the mission of teaching and its daily practices, in other words, how they interconnect the theoretical studies to daily basis activities into the classroom. The results show that the way the professors guide their practice is essential for the student to assume autonomy as regards the construction of scientific systematized knowledge, because it is his/her practice in this routine that will determine the degree of involvement in this plot.

Keywords: Classroom. Professor. Collaborative Observation.

\section{EL ESPACIO/ LUGAR DE LA ACTIVIDAD DOCENTE Y LAS TRAMAS QUE ENVOLVEN LA RUTINA DE LA SALA DE CLASE}

\section{RESUMEN}

El texto es una discusión de la rutina diaria del aula del profesor universitario, y tiene como objetivo investigar la práctica de los profesores de la Universidad Federal de Piauí, en el curso pedagogía que se manifiesta a diario, desde la relación enseñanza y el aprendizaje teniendo como cuerpo teórico Certeau (2008), Catani et al. (2005), Maseto y Abreu (1999), entre otros, y metodológico el dispositivo de medioación denominado de observación colaborativa que, según Paiva (2002) y Ibiapina (2005), puede definirse como una característica capaz de valorar la participación y colaboración que culminanen el proceso de pensamiento crítico como principios formativos, se potencializa a partir de las etapas de descripción, información, confrontación de teorías y de reconstrucción y prácticas inherentes en el proceso de enseñanza-aprendizaje. Con base en las observaciones de clases de 06 profesores de enseñanza superior, fue posible identificar como ellos establecen la relación entre los conceptos de Enseñanza, Aprendizaje y Docencia consideran fundamentales para la práctica de la enseñanza y su práctica diaria, es decir, cómo interconectan los estudios teóricos de la vida cotidiana al aula. Los resultados muestran que la forma en que el profesor imparte su práctica es esencial para que el estudiante puede tomar su autonomía con respecto a la construcción del conocimiento científico sistematizado, es el hacer esto todos los días lo que va a determinar el grado de participación en la trama.

Palabras clave: Sala de clase. Maestro. Nota de colaboración.

\section{INTRODUÇÃO}

Estudar o cotidiano da sala de aula significa imergir nas interações entre professor e alunos no ambiente natural em que elas ocorrem, tendo em vista a possibilidade de poder desvelar as diferentes formas que cada sujeito percebe e interpreta a realidade, ou seja, o significado que eles 
atribuem a essas interações. Assim, estudar a dinamicidade da sala de aula exige considerar como elemento fundamental a história pessoal de cada indivíduo membro deste lócus, bem como as reais condições em que esses se apropriam do conhecimento sistematizado.

Significa, tomar de um lado a situação concreta do aluno no que se refere a linguagem, cognição, imaginário, dentre outros, e a situação do professor considerando as condições de vida e de trabalho, expectativas, e concepções, e daí analisar de que maneira as formas de trabalho cotidiano que ali se manifestam podem facilitar a compreensão de como a escola vem confirmar a sua função social e educativa.

Torna-se importante compreender o significado de cotidiano como parte do dia-a-dia do sujeito em contextos variados e que muitas vezes se constituem em hábitos ou rituais. Para melhor compreensão buscamos apoio nos escritos de Michel de Certeau (2008, p. 31), quando afirma que

O cotidiano é aquilo que nos é dado cada dia (ou que nos cabe em partilha), nos posiciona dia após dia, nos oprime, pois existe uma opressão no presente. [...] o cotidiano é aquilo que nos prende intimamente a partir do interior. [...] o que interessa ao cotidiano é o invisível.

Nosso olhar para este tema de estudo tem sua justificativa assentada nas questões específicas do cotidiano da sala de aula, considerando ser esse o espaço/lugar da atividade docente. Assim, a opção por trabalhar com os professores do ensino superior respalda-se no fundamento de que eles são formadores de professores que atuarão na educação básica. Minha intenção, portanto, é abrir espaços para a discussão e construção de novos caminhos que sejam capazes de favorecer a esses professores elementos para um novo fazer pedagógico.

O interesse pela prática do professor nesta pesquisa se justifica, ainda, pela necessidade de entender como essa prática se manifesta no cotidiano, a partir da relação ensinar e aprender. Esse olhar implica considerar que essa prática se efetiva na sala de aula na qual o professor é o resultado do seu próprio trabalho isto é, se constitui na atividade da qual participa sem se 
limitar a ela uma vez que se apropria de saberes e experiências que não foram diretamente vivenciados por ele na sala de aula.

A ação de educar se reflete para fora do seu processo e, é nesse espaço do mundo exterior que o seu sentido se completa. Pensar a educação implica pensar a sociedade em que vivemos considerando a sua evolução e as diferentes concepções de homem manifestadas ao longo do processo de desenvolvimento da humanidade. É, portanto, a partir do fenômeno educativo que se efetivam as transformações sociais e culturais necessárias ao ser humano para que esse possa agir e interagir com seus pares, o que vai efetivamente caracterizar o processo educativo.

O trabalho docente é uma atividade consciente e sistemática que tem como centro o ensinar e o aprender e, nesse contexto, o processo de organização e operacionalização da ação docente se efetiva a partir do planejamento como responsável em promover a articulação da atividade escolar de construção do conhecimento com o contexto social.

Nessa perspectiva é relevante assinalar a reflexão crítica como elemento fundamental para que o professor, nos dias atuais, possa compreender como se desenvolve a sua prática e que resultados podem ser construídos na formação de seus alunos. Para tanto, é importante que o professor tenha clareza do seu papel na atividade ensinar/aprender, visto ser essa atitude que irá garantir o estabelecimento de elos entre o aprendiz e a sua aprendizagem.

O profissional docente é o responsável pela atividade de ensino a ser direcionada ao aluno, e a relação que se constrói entre ambos é parte de um processo abrangente pelo qual ele lida com os conteúdos. Nesse sentido, o trabalho do professor se desenvolve com fundamento nos três elementos básicos: o professor, os alunos e o saber. Esta relação irá determinar o perfil assumido por esse profissional, tendo por base sua perspectiva epistemológica e pedagógica.

De tal modo, para o professor comprometido em promover a aprendizagem de seu aluno, faz-se necessário desenvolver atividades didáticas com o intuito de intensificar seu raciocínio. Essa necessidade 
precede a tudo e, por isso mesmo, aponta a alternativa dos estilos de ensinar, pois o professor reconhece que os métodos são eficazes somente quando estão de alguma forma, associados com os estilos de pensar do aluno.

Essas associações irão favorecer o aluno na condução da sua atividade de aprender, quando o professor como par mais experiente criar situações que favoreçam sua aprendizagem. Essa ideia é a que se apreende de Vygotsky (2000), quando verifica teoricamente as relações entre aprendizagem e desenvolvimento e constrói o conceito de zona de desenvolvimento proximal.

Enquanto processo de socialização e contínua construção da cultura, a educação se efetiva em todas as instituições sociais. Mas na escola ela se reveste de características diferenciadas, tendo em vista ser nesse espaço que se efetiva uma educação intencional e sistematizada, que exige, dentre outros elementos, preparo, diretividade, rigor. Meirieu (2006, p. 68) nos esclarece que a escola não é somente lugar de passagem, ela é na sua plenitude,

[...] uma instituição onde as relações entre as pessoas, o conjunto da gestão cotidiana e todo o ambiente material conspiram etimologicamente, "respiram juntos" - para instituir uma forma particular de atividade humana fundada em valores específicos: o reconhecimento da alteridade, a exigência de precisão, de rigor e de verdade, a aprendizagem conjunta da constituição do bem comum e da capacidade de pensar por si mesmo.

Esse processo reflexivo afeta diretamente a sala de aula, por ser o ambiente físico no qual a aprendizagem se realiza. É nesse espaço que se desenvolve a trama da aprendizagem, e que, a partir dela, buscamos identificar como se efetiva a prática dos professores participantes desta pesquisa.

\section{PERCURSO METODOLÓGICO}

O estudo foi realizado com 06 (seis) professores do ensino superior que atuam no curso de Pedagogia da Universidade Federal do Piaú tendo como objetivo investigar como a prática desses docentes se manifesta no 
cotidiano da sala de aula a partir da relação entre os conceitos fundamentais ao exercício da docência e sua prática cotidiana

Para a organização dos dados, fizemos a opção foi pela observação colaborativa que na percepção de Paiva (2002) e Ibiapina (2005), pode ser definida como um recurso capaz de valorizar a participação e colaboração que culminam no processo de reflexão crítica, enquanto princípios formativos, se potencializando a partir das etapas de descrição, informação, confronto e reconstrução de teorias e práticas inerentes ao processo ensinoaprendizagem.

A observação colaborativa se efetiva a partir de três momentos distintos e interconectados: a pré-intervenção, a intervenção e a pósintervenção, que ao serem postas em prática, provocam um processo reflexivo capaz de desestruturar as velhas práticas de ensino, oferecendo, assim, possibilidades inovadoras capazes de modificá-la expressivamente. Sua principal característica está em possibilitar a descrição do contexto observado, quando o observador busca interpretar os resultados com o auxílio do observado que é requerido a retomar os momentos vividos pelo observador, tendo assim a oportunidade de exprimir-se por meio da reflexão longe do contexto da prática observada.

Neste sentido, para trabalhar com este dispositivo torna-se necessário a definição de algumas ações básicas para que sejam operacionalizadas no contexto da reflexão crítica. Na perspectiva de Contreras (2002), essas ações são: a descrição, a informação, o confronto e a reconstrução. Os aspectos contemplados nas fases de intervenção e de pós-intervenção foram construídos com base em Paiva (2002) e lbiapina (2004).

A ação de descrever procura compreender todos os momentos da prática docente; é nela que os submergidos, no caso os professores, iniciem essa empreitada considerando como ponto de partida a sua prática habitual, por ser essa o campo de articulação de conhecimentos, princípios, crenças e valores capazes de promover a tomada de decisão quanto ao que realmente deve ser feito. Na fase de intervenção foram considerados: o contexto da aula; quantidade de alunos; o assunto trabalhado e sua 
importância na formação dos alunos; objetivos definidos para a aula; a organização da turma; atividades realizadas na sala como suporte para a compreensão do assunto estudado. E na pós-intervenção foi considerado o seguinte questionamento: $O$ que motivou a escolha desse assunto?

A ação de informar se distingue pelo questionamento acerca das escolhas feitas, considerando que os participantes vão analisar a descrição de suas próprias ações para atingir a compreensão do seu fazer a partir do embasamento teórico que dá sustentação à sua prática. Na fase de intervenção foram apreciados os seguintes elementos: o foco principal do conteúdo; objetivos atingidos; conhecimentos trabalhados; dificuldades enfrentadas para estimular o aluno a participar; relações construídas entre a prática e o conteúdo objeto do estudo; relação entre o tema trabalhado e as atividades desenvolvidas. Os questionamentos que direcionaram a reflexão na fase de pós-intervenção foram: Que relação fez entre a prática e os conceitos já internalizados? De que maneira as suas escolhas teóricas afetam a sua prática?

$\mathrm{Na}$ ação de confrontar, os participantes têm a oportunidade de examinar, tanto os vários contextos para melhor compreender a sua prática, quanto às inúmeras concepções que dão suporte às suas ações. Na fase de intervenção foi ponderado o seguinte aspecto: Tipo de aluno que está sendo formado. Na fase de pós-intervenção foram elencados os seguintes aspectos: construção do perfil docente; contribuições do conhecimento trabalhado na aula para o aluno no exercício da profissão; importância do conhecimento trabalhado no processo de transformação da realidade do aluno; limites da sua prática; fundamentos teóricos para sanar as dificuldades; conceitos que serviram de suporte na construção de sua prática; relação entre esses conceitos e a sua formação profissional.

Finalmente, na ação de reconstruir, os participantes passam por um processo de redefinição dos conceitos e valores que dão sustentação tanto aos aspectos pessoal e profissional, visto que, ao apreender que a realidade é dinâmica, o profissional poderá operar diferentemente, buscando sempre reconstruir as suas ações no sentido de cada vez mais aperfeiçoá-las. Na 
fase de intervenção foram apreciados elementos como: diferentes formas de preparar a aula; ações para motivar o aluno no processo de aprendizagem e ampliar o pensamento crítico reflexivo. Na fase de pósintervenção foram enfatizados os seguintes pontos: melhoria no desenvolvimento profissional do professor; relação entre o seu trabalho hoje e o realizado no início de sua carreira; elementos a serem trabalhados para modificar seu contexto de atuação;

As fases propostas se efetivaram neste estudo através do contato individual mantido com os professores, quando apresentamos e explicamos a metodologia, o plano de observação, além do roteiro que dirige todo o processo. Cada professor foi orientado para responder às questões constantes no roteiro, que são relativas à fase pós-interventiva. A fase de intervenção foi realizada nas salas de aula, em um total de 02 (duas) aulas, por sala ${ }^{2}$, oportunidade em que a observação foi efetiva realizada.

Estes apontamentos serviram para a apreciação da prática, em sala de aula, de cada docente envolvido para compreender como ele estabeleceu a relação entre o discurso ancorado em referenciais teóricos e o seu cotidiano, o que me garantiu, assim, analisar como ele se apropria das teorias que fundamentam sua atividade.

Considerando a etapa de pós-intervenção efetivada pelos pesquisadores, a partir da observação colaborativa, buscamos destacar, no decorrer das reflexões realizadas, que saberes foram evidenciados no processo de formação desses profissionais que possibilitaram a compreensão da sua prática cotidiana. Verificamos, ainda, como foram sendo construídos esses saberes, visto que o diálogo estabelecido durante as interlocuções permitiu essa identificação. Esta é, também, uma forma de pôr à prova a ênfase dada, no decorrer desta pesquisa, aos conceitos fundamentais para a docência, verificando sua importância nos diferentes contextos de atuação profissional.

\footnotetext{
${ }^{2}$ Cada aula corresponde a 04 (quatro) horas nas turmas de Prática Pedagógica na Escola, totalizando 08 (oito) horas. Somente na turma de Avaliação, a aula corresponde a 02 (duas) horas, totalizando 04 (quatro) horas nesta disciplina.
} 


\title{
3 RESULTADOS E DISCUSSÕES
}

\subsection{O cotidiano da sala de aula}

Pensar a sala de aula como o espaço no qual grande parte do trabalho docente se desenvolve é admitir ser este o lugar em que o professor tem maior proximidade com seus alunos. Ali, a aula não se constitui de algo dado, mas em atividade que se faz em parceria alunos e professor na diferença dos papeis que cada um assume nesse contexto.

Nessa perspectiva Ponce (1989, p. 77-78) esclarece o sentido verdadeiro da aula ao afirmar que

\begin{abstract}
A aula é o espaço/tempo privilegiado da comunicação didática. [...] É uma relação intersubjetiva, supõe, portanto a presença de sujeitos interagindo entre si. Em outras palavras, tanto o aluno quanto o professor devem ser vistos como sujeitos do processo ensinoaprendizagem, e neste sentido possuem uma igualdade para que tal relação se estabeleça. [...] Porém, aluno e professor possuem diferentes níveis de compreensão da realidade e o diálogo em aula não deve ignorar este dado, mas sim incorporá-lo como dado fundamental.
\end{abstract}

É, portanto, na sala de aula, que o professor faz o que sabe, assumindo nesse fazer uma autonomia que se manifesta a partir de sua concepção de educação, de homem e de escola, levando em consideração o seu próprio papel enquanto educador, visto que the é dado o poder de decisão quanto à forma de conduzir e avaliar a atividade de ensino. Quando se analisa mais detidamente a prática docente, esse procedimento, conforme nos esclarecem Catani; Sousa; Vicentini; Silva (2005, p. 46),

[...] fornece aos professores elementos para pensarem alternativas de ação que mobilizem os saberes oriundos da experiência vivenciadas no exercício do magistério e os saberes provenientes de uma elaboração acadêmica, de modo a potencializar a sua capacidade de identificar problemas, pensar soluções e construir práticas, avaliando a sua realização e levando em conta as inúmeras dimensões intervenientes no processo de ensino-aprendizagem.

Como contribuição a este estudo, Maseto e Abreu (1999) destacam que a sala de aula se configura como lugar de espaço e tempo no qual os sujeitos envolvidos nas atividades de ensinar e aprender se associam para, 
em conjunto, realizarem ações que se transudam pelas interações de como estudar, ler, discutir e debater, o que vai garantir diferentes formas de compreensão tanto do professor que ensina, quanto do aluno que aprende.

Partindo desse entendimento, buscamos, com base nas observações realizadas nas salas de aula de 06 (seis) professores do ensino superior, identificar como eles estabelecem a relação entre os conceitos fundamentais ao exercício da docência e sua prática cotidiana e de que maneira esses professores interconectam os estudos teóricos ao cotidiano da sala de aula.

\section{Um olhar sobre a prática de Anavi}

A aula observada foi ministrada na disciplina Prática Pedagógica na Escola V, do Curso de Pedagogia da Universidade Federal do Piauí. O assunto trabalhado foi a observação colaborativa, como procedimento facilitador na coleta de dados em uma pesquisa. Para trabalhar esse conteúdo, a professora iniciou fazendo a discussão de dois textos. "Reflexividade: estratégias de formação de professores" (IBIAPINA, 2005), em que ela explicou cada uma das fases que compõem a observação colaborativa, destacando, sempre, que o processo reflexivo é exigido tanto por parte do observador quanto do observado. E "A prática pedagógica como componente profissionalizante da formação de professores" (IBIAPINA, 2005), a partir do qual foi feita a distinção entre a observação descritiva e a observação reflexiva, destacando que a segunda é um processo de troca, de partilha.

Ao trabalhar esse conteúdo, a professora buscou desenvolver junto aos alunos uma prática de observação que privilegiasse as ações de descrever, informar, confrontar e reconstruir teorias e práticas docentes.

Embora a professora tenha o pleno domínio da palavra, e isso foi demonstrado em sua exposição oral, ela abriv espaço para que os alunos se colocassem nessa construção coletiva. Tal possibilidade ficou mais evidente quando a professora construiu, com a colaboração dos alunos, o roteiro de observação, explicando cada um dos elementos do plano de observação a 
ser utilizado como atividade de estágio. Foi possível perceber que, nessa disciplina, os alunos estão sendo formados com base na reflexão crítica.

Fazendo uma análise da prática de Anavi, destacamos uma coerência entre a perspectiva teórica (Marx, Vygotsky e Leontiev) por ela adotada e sua relação com a prática efetivada, visto que a professora tem consciência sobre sua atividade enquanto docente, isto porque há uma estreita relação entre os conceitos por ela internalizados, ao longo do seu processo formativo, os quais utiliza sempre em uma perspectiva crítica.

O exercício da crítica na formação de professores, com base em Arroyo (2000), tem papel preponderante, porque amplia uma visão consciente das inúmeras determinações do social e do político, no contexto da escola, enquanto instituição social, pois se compreende que estabelecer processos interativos entre o mundo pessoal do aluno e a realidade social vai favorecer o seu desenvolvimento pleno.

\section{Um olhar sobre a prática de Dina}

A partícipe iniciou as atividades repassando o material que seria utilizado no estágio. O conteúdo da aula consistiu na orientação desse material e na socialização dos projetos de oficina pedagógica que foram desenvolvidos como atividade de estágio em seu decorrer.

Foi repassado o material a ser utilizado no estágio, constituído de duas fichas: a de estágio propriamente dita e a de avaliação do estágio para serem preenchidas pela professora regente da sala de aula. O assunto trabalhado foi, basicamente, a orientação desse material e a socialização dos projetos de oficina, que foram desenvolvidos durante o estágio. Trata-se de uma atividade interessante, tendo em vista que oportuniza aos grupos um envolvimento maior nas várias atividades a serem desenvolvidas na escola, inclusive exigindo a participação de outros segmentos da escola, como, por exemplo, a coordenação, a direção etc.

Os objetivos definidos para esta aula constituíram-se em orientar os alunos quanto ao preenchimento das fichas a serem utilizadas no decorrer do estágio, bem como discutir a organização das oficinas; destaque-se que 
ambos foram plenamente atingidos. A turma estava organizada em círculo e os integrantes dos grupos estavam próximos, o que facilitou a apresentação das propostas de oficina. No que diz respeito à participação dos alunos, podemos dizer que foi muito boa, visto que, no decorrer das apresentações, as manifestações e contribuições dos demais grupos foram constantes.

O tema trabalhado tinha como foco orientar os alunos estagiários quanto ao processo de organização de uma oficina, considerando que a partir das descrições e orientações ele possa compreender a importância dessa atividade no contexto de sala de aula. O conhecimento trabalhado serviu como referência para que o aluno possa construir, em outros momentos da sua prática, atividades semelhantes àquelas realizadas no estágio.

Foi possivel observar que a professora é bastante acessivel e aberta ao diálogo, dando oportunidade a todos os alunos de interferirem no decorrer de sua exposição. A discussão dos projetos de oficina pedagógica serviu para os alunos compreenderem a importância dessa atividade na escola.

No contexto da disciplina, a perspectiva é no sentido de formar o aluno com base na autonomia e na cooperação, uma vez que se trata de uma atividade coletiva, em que cada membro da equipe tem a oportunidade de demonstrar seus conhecimentos e habilidades perante 0 grupo.

De modo geral, a análise que fazemos da prática de Dina demonstra que esta, ao selecionar essa atividade, considerou alguns aspectos diretamente relacionados com o processo de formação dos futuros professores. Ela propõe aos alunos que esse conhecimento se construa coletivamente nos pequenos grupos, para, em seguida, serem socializados em sala de aula para os demais.

\section{Um olhar sobre a prática de Andorinha}

A aula foi ministrada na disciplina Avaliação Educacional, no Curso de Pedagogia. A professora iniciou a aula fazendo uma exposição oral sobre os 
diferentes tipos de avaliação e sobre a avaliação na educação básica. À medida que ia falando, alguns tópicos iam sendo destacados no quadro.

No decorrer da exposição, os conhecimentos dos alunos foram considerados pela professora, que buscou, a partir dessas intervenções, fazer aflorar cada vez mais as reflexões em torno do conhecimento que estava sendo trabalhado. Isso foi perfeitamente observado quando a professora os incentivou a analisar sua prática a partir dos modelos avaliativos presentes em suas ações, pois muitos deles já são professores.

A ênfase maior em sua explicação foi dada sobre as várias dimensões assumidas pela avaliação. A aula transcorreu nos moldes tradicionais; pudemos observar também que ocorreram alguns questionamentos isolados sobre a temática. No contexto formativo, consideramos este tema de extrema importância no processo de formação inicial dos futuros professores, visto que a avaliação é um dos elementos fundamentais no desenvolvimento do processo ensino-aprendizagem.

Após a exposição, a professora solicitou que os alunos fizessem a leitura do texto "Avaliação na Educação Básica: ampliando a discussão" (DEPRESBITERIS, 2001), como uma oportunidade de refletir sobre o conteúdo exposto oralmente.

A compreensão adquirida da prática de Andorinha consiste no fato de que essa temática é fundamental no processo de formação inicial do futuro professor, principalmente, por se tratar de um dos elementos essenciais do processo de ensino e aprendizagem.

A partir da observação realizada, foi possível constatar que a professora adota uma postura tradicional ${ }^{3}$, quando expõe o conteúdo e, apesar de abrir espaços para a discussão, essa não se efetivou em uma perspectiva de reflexão, em que os alunos pudessem argumentar sobre as possíveis questões que sua exposição poderia gerar o que certamente

3 Estamos considerando postura tradicional como uma prática que não possibilita a participação efetiva dos alunos nas discussões e considerações sobre o conteúdo trabalhado na sala de aula. 
deveria despertar, nesse aluno, a possibilidade de refletir criticamente o tema trabalhado.

\section{Um olhar sobre a prática de Santos}

Esta aula foi ministrada na disciplina Prática Pedagógica na Escola V, no Curso de Pedagogia. Os alunos perfazem um total de 35 (trinta e cinco), estão em fase de estágio obrigatório nas escolas de Ensino Fundamental. 0 assunto da aula foi a socialização das atividades realizadas no decorrer do estágio.

Inicialmente, a professora fez algumas colocações no sentido de direcionar os relatos e, em seguida, passou a palavra aos grupos para que fizessem suas colocações. Cada grupo fez seu relato, destacando as dificuldades e as possíveis situações que poderão ocorrer em seu cotidiano, e o processo de socialização das construções coletivas sobre essas dificuldades serviu como base para que os alunos se utilizem dessas orientações em momento posterior, de acordo com sua necessidade.

Observamos que a possibilidade de o aluno refletir não só sobre a sua prática, mas principalmente pela garantia de interagir com os colegas, tornou essa atividade de grande relevância no contexto dessa formação. Os objetivos definidos para essa aula foram plenamente atingidos.

Cada grupo fez a socialização da experiência e, no final, a professora destacou alguns pontos considerados importantes nessa construção, tais como: a identificação e superação de obstáculos, a aprendizagem que se efetivou a partir da dificuldade do outro e a possibilidade de refletir sobre sua ação para, a partir daí, aprimorá-la.

A compreensão adquirida da prática da partícipe revela que ela está buscando desenvolver um trabalho em que o ato reflexivo esteja sempre presente, visto que, quando se trabalha na perspectiva da reflexão crítica, a possibilidade de desenvolver a autonomia profissional, nos futuros professores, que estão sendo formados se torna mais evidente. 


\section{Um olhar sobre a prática de Júlio}

A aula foi ministrada na disciplina Prática pedagógica na Escola IV, no Curso de Pedagogia. O assunto tratado foi sobre a socialização das experiências vivenciadas na prática do estágio. Inicialmente o professor pediu aos grupos que relatassem suas experiências, contemplando os seguintes tópicos: o desenvolvimento do trabalho, as construções positivas em termos de experiências práticas, a avaliação do estágio enquanto prática coletiva e a contribuição da prática para os alunos e professores da escola campo de estágio. O professor organizou a sala em um grande grupo, o que facilitou a interação direta com a turma, abrindo espaço para que todos os alunos fizessem suas colocações, o que ajudou bastante na compreensão de como essa atividade se efetivou. O professor aproveitou esse momento de socialização buscando estabelecer a relação entre os conhecimentos teóricos agregados à prática do estágio.

Foi possível observar, ainda, que os alunos estão sendo formados, tendo como parâmetro a cooperação entre os pares, visto que, nessa perspectiva, é dada ao aluno a oportunidade de manifestar seus conhecimentos, como possibilidade de fortalecimento e ampliação dos conhecimentos gerados pelo grupo. De maneira geral, pudemos observar que a prática desse professor está associada ao princípio da dialogicidade, que culmina com a possibilidade de construção coletiva pelos participantes dos grupos.

\section{Um olhar sobre a prática de Lena}

A aula foi ministrada na disciplina Prática Pedagógica na Escola II, no Curso de Pedagogia da UFPI. O assunto trabalhado pela professora foi a Formação de Professores no contexto Educacional, a partir dos modelos formativos, e foi dado destaque para o modelo crítico-reflexivo.

As atividades se desenvolveram em forma de seminário, e, à medida que os grupos iam se apresentando, a professora abria espaço para a discussão sobre o que tinha sido colocado pelo grupo. 
Durante suas intervenções, a professora procurou deixar claro que, no período atual, torna-se imprescindível que o futuro professor tenha consciência da necessidade de refletir de maneira crítica, pois essa postura irá contribuir no sentido de criar alternativas de mudanças em sua prática.

Apesar de a professora lançar alguns questionamentos, foi possível observar pouca participação por parte dos alunos, o que fez com que não fossem atingidas suas expectativas.

Foi possível observar, ainda, que a professora trabalha na perspectiva da reflexão, entretanto, não tem internalizado o ato de refletir como um processo capaz de gerar transformações, tanto na sua prática, quanto na formação dos seus alunos. Essas colocações são reforçadas por Vygotsky (2000), quando afirma: se um conceito é internalizado, ele passa a fazer parte das várias ações manifestadas pelo sujeito, provocando, portanto, transformações na prática de quem o internaliza.

\subsection{Por que ressignificar?}

O papel do professor no contexto da nova realidade educacional não é mais o de simples repassador de conhecimentos, mas daquele que garante aos seus alunos a possibilidade de adquirir estratégias de descoberta, oferecendo a eles a oportunidade de refletir sobre como esse processo se efetiva.

Ao longo de sua trajetória, o professor é, em todos os momentos, o resultado de seu percurso pessoal e profissional. Contudo, é nesse percurso que ocorrem as mudanças conceituais a partir de dois contextos de interação: a sua prática cotidiana e os grupos reflexivos que são constituídos por seus pares.

Nesse sentido, o processo de desenvolvimento do professor tem como referência a dimensão individual, voltada especificamente para o seu próprio eu, cuja construção se dá em nível consciente e inconsciente, e a dimensão coletiva que ele constrói, com base nas representações oferecidas por seu campo de atuação, possibilita, dessa forma, a reconstrução do seu universo profissional. 
Com base em Cavaco (1993), podemos afirmar que o professor aprende com base nas práticas que realiza, interagindo com outros pares, no caso os alunos, enfrentando situações, refletindo as dificuldades, enfim, reajustando-se às suas formas de ver e de refletir seu próprio contexto de atuação. Nessa perspectiva, buscamos nas narrativas dos pesquisadores os indicadores do seu proceder em relação aos saberes docente.

Convém enfatizar que a docência constitui-se como atividade cuja essencialidade está intimamente relacionada aos vários saberes produzidos, e sua utilização na prática cotidiana do profissional docente. Essa relação evidencia que aquilo que o professor pensa e faz traduz-se no seu saber fazer, que é resultado de todo processo de aquisição de conhecimentos formais, bem como de seu saber prático, no sentido de melhor compreender a sua práxis.

O professor é uma peça fundamental na engrenagem que constitui o processo educativo no que diz respeito a promoção de inúmeras modificações necessária ao ensino. Partindo dessa possibilidade, esse profissional será chamado a elaborar e reelaborar de maneira crítica sua própria prática.

Assim, acreditamos nas possibilidades de termos escolas que desde cedo preparam os seus cidadãos para ter voz ativa, sendo dono de opiniões, pontos de vista; que participem de debates, discussões; que possam cumprir seus deveres e lutarem por seus direitos com autonomia; que possam conquistar sua liberdade de ir e vir agindo na participação das práticas sociais existentes, com dignidade. Importante ressaltar que trabalhar com a produção de sentido no espaço escolar aconteceria no momento em que o trabalho pedagógico da escola conquistasse sua autonomia. Isso possibilitaria a toda a comunidade escolar uma participação efetiva, desde a construção do projeto político-pedagógico até uma simples decisão que venha ocorrer no espaço escolar.

Nesse aspecto, Villas Boas (2002) pode esclarecer o que estamos pensando, quando comenta que o que dá direito de autonomia não é o professor ensinar o que quiser, da maneira como quiser e a quem quiser, mas 
- compromisso de garantir que cada aluno aprenda o que necessita aprender. Ter autonomia não significa desvincular-se do conjunto de normas educacionais básicas, mas criar os melhores meios de aplicá-las. A escola que a sociedade democrática requer é aquela capaz de implementar o seu próprio projeto pedagógico, elaborado coletivamente, devidamente atualizado, divulgado e avaliado por todos os interessados. Isso pressupõe competência, seriedade, comprometimento e rigor.

\subsection{E a Observação Colaborativa o que revelou?}

Considerando a etapa de pós-intervenção efetivada pelos interlocutores, a partir da observação colaborativa, buscamos destacar, no decorrer das reflexões realizadas, que saberes foram evidenciados no processo de formação desses profissionais que possibilitaram a compreensão da sua prática cotidiana. Verificamos, ainda, como foram sendo construídos esses saberes, visto que o diálogo estabelecido durante as interlocuções permitiu essa identificação. Esta é, também, uma forma de pôr à prova à ênfase dada, no decorrer desta pesquisa, aos conceitos fundamentais para a docência, verificando sua importância nos diferentes contextos de atuação profissional. Comecemos analisando a fala que se segue:

Quando eu fiz o curso de Pedagogia aqui na universidade houve algumas disciplinas que eu tive uma certa dificuldade de aprendizagem. Então, em razão dessas minhas dificuldades eu fui buscar e construindo um modelo de formação enquanto formadora para fazer com que o meu aluno possa aprender com facilidade. [...] então quando eu penso em aprendizagem, eu vou pensar em formação o que foi que eu aprendi se foi uma aprendizagem traumática eu vou fazer o Máximo possível para que a aprendizagem do meu aluno não seja traumática. Quando eu vou pensar um modelo de docência eu vou pensar no melhor modelo possível de docente porque eu estou buscando me transformar num docente que tenha condições de ajudar meus alunos. (Extraído da etapa de pós-intervenção realizada com Dina).

A professora tem consciência da importância das aprendizagens decorrentes da formação inicial, no entanto, destaca o fato de ter aprendido a estudar, a buscar os conhecimentos necessários à sua prática. Esse conhecimento Ihe proporcionou um saber-estudar, um saber-buscar 
que veio ao encontro de suas necessidades enquanto docente. Sobre essa questão, outro partícipe também se manifesta:

Eu tenho a firme convicção que do ponto de vista reflexivo, a socialização do conhecimento é fundamental, a socialização da experiência em especial.[...] eu fui muito marcado na minha formação pelo pensamento freireano. Paulo Freire fez uma diferença muito grande não só pelos preceitos de dialogicidade que ele introduziu na educação, de conscientização, mas também pelo fato de ele permitir uma revalorização do saber, de permitir que a gente reveja os saberes de diferentes sujeitos com outros olhos, com olhos de quem pode valorizar o trabalho da experiência o trabalho não acadêmico com igual cuidado com que a gente avalia e valoriza o trabalho de um mestre de um doutor na academia. (Extraído da etapa de pós-intervenção realizada com Júlio).

Para esse professor, está claro que sua competência profissional se manifesta a partir de um corpus teórico que ele dispõe, e que foi sendo construído com base nas teorias que permearam a sua formação inicial. Os saberes que fazem desse professor o que ele é e o que ele sabe está interrelacionado; e ao destacar seus saberes pessoais o faz relacionando com conhecimentos oriundos dessa formação inicial, como, por exemplo, os fundamentos da educação, ao se referir a Paulo Freire.

Na fala a seguir, é possível perceber a preocupação da partícipe com relação à importância que deve ser atribuída ao domínio do conteúdo a ser ensinado ao destacar a importância em estar atualizada, pois assim acredita na possibilidade de garantir a seus alunos uma formação coerente com os fundamentos que dão sustentação à profissão.

Eu sou tipo uma privilegiada, eu me considero, porque todas as minhas escolhas teóricas não eram tão minhas elas eram impostas pela instituição, mas elas vinham ao encontro das minhas carências, as minhas faltas e necessidades eu precisava ter vivido passado por isso e aí eu comecei mesmo a buscar outros conteúdos já pra...a gente vai crescendo ne. Muitas vezes você tem um conhecimento tão curto e escolhe os conteúdos ali mesmo e você já tendo uma gama de conhecimentos eles vão se aprofundando, então eu tive esse cuidado de escolher aquilo que eu sabia ia responder as angústias dos meus alunos as inquietações deles eu sempre fazia muitos questionamentos e a gente colocava num caderno e depois a gente ia tentando responder no decorrer do curso. Eu buscava sempre os conteúdos que viessem atender as necessidades dos meus alunos. (Extraído da etapa de pós-intervenção realizada com Lena). 
A ênfase dada por esta professora ao saber ensinar recai sobre sua capacidade de escolha e síntese, considerando, além das necessidades educativas dos alunos, o próprio contexto em que serão utilizadas.

O trabalho interativo exige a capacidade de saber negociar e saber tolerar. A negociação está na base do trabalho do professor, pois, para intervir na sala de aula, ele necessita da colaboração do outro, e isso só será possível se o outro, no caso o aluno, estiver mobilizado e motivado, o que requer a negociação constante e a tolerância para trabalhar com a individualidade de cada um, buscando promover a integração em torno da colaboração mútua. Essa possibilidade fica evidente na expressão da professora.

[...] como eu venho trabalhando desde a minha tese de doutorado com a perspectiva da inter-relação, da mediação com conceitos que são trabalhados na perspectiva sócio histórica, que são conceitos definidores da formação humana, a linguagem e o próprio conceito de formação, eu fiz opção por uma prática que correspondesse a essa opção teórica que eu fiz dentro da perspectiva sócio histórica. Então eu selecionei dentre várias possibilidades que eu tinha de trabalho aquela que eu achei que seria a que mais correspondia aquilo que eu acredito, que são os princípios teóricos metodológicos da pesquisa colaborativa. Então os conceitos que eu internalizei ao longo do meu processo formativo e que vieram se definir com mais concretude no meu percurso profissional [...] eu procurei fazer essa transposição para a minha prática optando por uma metodologia de trabalho que pudesse aliar essa formação, esses princípios teóricos com uma ação mais participativa, mais colaborativa e que a gente pudesse sair dos muros da universidade e pudesse contribuir com uma formação para que esses alunos tivessem uma visão de escola numa perspectiva mais participante, mais colaborativa e que pudesse realmente ter um conceito de prática de ensino e de formação que pudesse contribuir no seu percurso de desenvolvimento profissional e não fosse uma coisa que se restringisse a uma atividade acadêmica. (Extraído da etapa de pós-intervenção realizada com Anavi).

Podemos observar, nesse depoimento, que a capacidade de a professora produzir refletindo sobre a prática depende, em grande parte, de sua formação teórico-epistemológica, pois é esta formação que lhe permite refletir de forma crítica e perceber as relações que se manifestam a partir dessa prática. Estas colocações são reforçadas por Fiorentini, Souza Júnior e Melo (2003, p. 319), quando afirmam que: 
O saber do professor, portanto, não reside em saber aplicar o conhecimento teórico ou científico, mas sim saber negá-lo, isto é não aplicar pura e simplesmente este conhecimento, mas transformá-lo em saber complexo e articulado ao contexto em que ele é trabalhado/produzido.

Neste sentido, buscamos identificar como os professores fazem a reflexão de sua prática, a partir da possibilidade de transformá-la, tendo em vista que é preciso inovar para se ter qualidade naquilo que se faz. Nessa perspectiva reconhecer que o profissional docente é capaz de refletir sobre - que faz e daí produzir saberes específicos é conceber esse profissional como um ser capaz de atuar no dia-a-dia, tendo a reflexão como perspectiva de ressignificação de sua atividade prática.

No decorrer do processo de formação, os professores, inicialmente, se apropriam dos conhecimentos disciplinares para que possam aplicá-los em situações cotidianas da prática. Tardif (2002, p. 273) enfatiza que "o fazer está subordinado ao conhecer", isso quer dizer que, para que o futuro professor aplique os conhecimentos adquiridos no decorrer do processo de formação, com vistas a solucionar problemas surgidos na prática, ele precisa, primeiramente, dominar esses conhecimentos.

No que se refere aos estudos sobre os saberes da docência, Tardif (2002) e Pimenta (1999) têm destacado que os saberes da experiência se constituem em parte dos fundamentos da prática desse profissional. São esses saberes que dão a base de sustentação à prática docente, e somente através dessa prática é que eles se manifestam.

O contato com os alunos e as reais condições nas quais os professores constroem sua vida profissional oferece inúmeras aprendizagens, tais como: a aquisição de saberes para agir em diferentes situações, trabalhar contextos variados e, principalmente, identificar e extrair do corpus teórico aquilo que é substancial à aprendizagem de seus alunos. Isso vem reforçar a ideia de que os professores não fazem uso de um saber único, mas de vários saberes, sendo impossível encontrar uma unicidade teórica para esses saberes. 
Quando perguntamos aos professores sobre as verdadeiras razões de suas ações, observa-se uma preocupação excessiva em se justificar e apresentar elementos que motivam as suas decisões. Ao responderem esses questionamentos, eles apresentam razões práticas que embasam o seu modo de agir. As justificativas apresentadas por eles, conforme nos esclarece Therrien (2002), estão associadas ou a resultados empíricos ou a saberes próprios da experiência docente.

Nosso interesse pela prática do professor nesta pesquisa se justifica especificamente pela necessidade de entender como essa prática se manifesta no cotidiano, a partir da relação ensinar e aprender. Esse olhar implica considerar que essa prática se efetiva na sala de aula, na qual o professor é o resultado do seu próprio trabalho. Vejamos como o partícipe destaca essa prática:

Quando eu entendo a importância do conhecimento de mundo que cada sujeito tem, isso faz com que hoje eu tenha uma tendência grande a me aproximar dos saberes da experiência olhar para aquele professor que está em sala de aula trabalhando lá dentro da sua simplicidade, perceber que saberes esse professor tem, o que ele construiu o que é que esse professor que tem uma experiência o que é que ele pode nos ensinar. Neste sentido eu acredito que não dar mais para conceber [...] um conhecimento puramente acadêmico e válido em si mesmo. Então esse meu olhar ele faz com que as minhas sugestões de prática elas estejam voltadas para 0 diálogo, para a troca, para a experiência, para o trabalho coletivo, para eu ver como o outro está fazendo, para me espelhar neste outro também. (Extraído da pós-intervenção realizada com Júlio).

Podemos observar que, para este professor, o seu fazer se explica a partir das experiências que foram sendo construídas ao longo de sua prática e construções teóricas. Ele acredita que a experiência é a chave para um fazer consciente, buscando situações positivas que possam servir de suporte ao desenvolvimento da prática.

A experiência do trabalho não é somente o espaço em que os conhecimentos são utilizados, mas é em si própria um conhecimento do 
trabalho, é a reflexão, a tomada de consciência, a apropriação e ressignificação do que o docente sabe dentro daquilo que sabe fazer, com vistas a produzir a própria prática profissional. Isso fica evidente no depoimento desta professora, ao fazer referência às atividades escolhidas para o desenvolvimento de sua disciplina.

Nós escolhemos essa estratégia porque dentre as que existem, é uma estratégia que consegue dar conta de vamos dizer dentro do modelo que nós optamos por trabalhar, de fazer essa interligação entre o cotidiano da sala de aula, a universidade e a universidade contribuindo para que 0 aluno, para que o professor possa ver o estagiário com outros olhos e ao mesmo tempo também contribuir para que ele possa ter uma experiência de sala de aula nessa troca que nós estamos denominando de observação colaborativa. [...]. Então a nossa perspectiva de opção por essa prática foi nesse sentido tentando aliar os conceitos que a gente já vem trabalhando dentro da perspectiva sócio histórica com uma prática que pudesse realmente mostrar para esses alunos que eles tem uma grande contribuição para dar a escola. (Extraído da etapa de pós-intervenção realizada com Anavi).

Na visão de Tardif, Lessard e Lahaie (1991), os saberes da experiência fundamentam a prática do professor, e através dela são revelados, portanto, mais do que no referencial teórico construído na universidade, no processo de formação, e que dá suporte ao seu trabalho, os professoras acreditam que a fonte do seu saber está nelas próprias, e que essa proximidade com as teorias serviu para ampliar e redimensionar seus conhecimentos. É nesse sentido que a partícipe se manifesta.

Eu vejo é que a cada dia no meu processo de aprendizagem, eu venho melhorando esse perfil ele vem se definindo com mais clareza, eu faço opções mais conscientes, eu faço opções por práticas com argumentos que são próprios da cultura docente, eu sei argumentar em favor das minhas opções, eu sei dizer o porquê dessas minhas escolhas que eu acho que antes eu não sabia, eu fazia dentro das condições que eu tinha e dos conhecimentos que eu tinha acesso.[...] então, é nessa perspectiva de fazer com que o aluno perceba essa necessidade de refletir e da colaboração de outras pessoas no seu processo de formação. E esse conhecimento ele só é importante para transformar a realidade do aluno quando ele tem consciência, quando ele percebe, quando ele pratica, quando ele vê os resultados que traz os avanços que isso pode possibilitar no seu processo de formação. (Extraído da etapa de pós-intervenção realizada com Anavi). 
Outro elemento destacado por Anavi diz respeito às questões específicas, relacionadas a sua prática diária - o estágio. Os partícipes que estão nesse campo de atuação se colocaram diante das inúmeras dificuldades por eles enfrentadas. Nesse sentido, foi possível identificar uma diversidade de ações a partir do estágio, que nos oferecem os elementos necessários, para identificar como essa prática vem sendo efetivada. Tivemos a oportunidade de resgatar esse contexto, buscando mostrar como alguns partícipes se manifestam.

Essas escolhas teóricas elas se encaminham para as opções práticas para a atividade mesmo do fazer docente. Então, esse princípio em termos de formação crítica de querer formar o aluno reflexivo de querer formar um aluno crítico e não ficar só no discurso, porque a gente sabe que no projeto pedagógico do curso uma das linhas de formação é essa, mas que a gente ver nas discussões as dificuldades que a gente tem de concretizar essa linha de concretizar isso, de realmente sistematizar formar um aluno crítico e reflexivo por meio de estratégias que possa sistematizar essa reflexão crítica [...] mostrando realmente através de uma prática que dar resultados de que é possível sistematizar essa reflexão crítica no cotidiano das atividades docentes e principalmente de que 0 professor não se desenvolve profissionalmente sozinho ele precisa de outros olhares, que ele precisa de troca, que ele precisa de outras pessoas que ajudem nesse processo de desenvolvimento. (Extraído da etapa de pós-intervenção realizada com Anavi)

É possível perceber, na expressão da partícipe, que as dificuldades enfrentadas na Instituição não impedem que o professor formador busque novas perspectivas, novas formas de inovar o estágio, considerando essa atividade como um princípio emancipatório.

Esse estágio que nós estamos desenvolvendo é nesse sentido de fazer com que o aluno tenha autonomia de pensamento, autonomia de ideias, autonomia de buscar [...] novos conhecimentos e acima de tudo oferecer ferramentas para que esse aluno reflita a sua prática e possa sistematizar essa prática de forma cientifica. [...] Nós não estamos querendo formar um aluno para que ele encontre tropeços. Eu sei que existem certas dificuldades, mas nós estamos tentando aproximar o máximo possível dessa realidade fazendo com que o aluno saia com algum tipo de conhecimento que possa fazer com que ele desenvolva uma prática que realmente faça a diferença. (Extraído da etapa de pós-intervenção realizada com Dina) 
Podemos perceber, neste depoimento, uma preocupação bastante acentuada, no que diz respeito à necessidade de reflexão nesse processo formativo; entretanto não fica evidente o valor dessa atitude no desenvolvimento da prática, no sentido de promover a integração e o interesse comum, como um princípio formativo. Esses elementos são muitas vezes questionados pelo professor que recebe o estagiário, e isso fica patente nas colocações a seguir.

É possível uma prática inovadora, é possível uma prática diferente e isso pode transformar a realidade do professor. É essa a importância que eu vejo de mostrar que pode ser diferente. E que em qualquer espaço essa prática pode ser feita. [...] quando os alunos chegam lá eles encontram já o professor desacreditado que não gostam mais de fazer o que estão fazendo [...] eles conseguiram mostrar que pode ser diferente. (Extraído da etapa de pós-intervenção realizada com Santos)

Nas palavras da professora, fica clara a necessidade de se modificar essa imagem negativa a que o estágio curricular está sendo submetido mostrando que é possível romper com esses limites, bastando, para tanto, ter compromisso com o processo formativo pelo qual se é responsável.

Finalmente, destacamos um ponto que é de extrema relevância para o desenvolvimento da prática dos professores formadores, e que diz respeito à necessidade de envolvimento, integração e até mesmo intervenção institucional, considerando a importância, e, principalmente, a responsabilidade que a Universidade assume nesse processo formativo. No depoimento a seguir, esses elementos estão em evidência, e cada partícipe, que atualmente está atuando nesta etapa de formação, demonstra essa preocupação, no sentido de buscar redimensionar o estágio, até como uma possibilidade inicial de integração e colaboração por parte dos professores envolvidos.

No início da disciplina sempre se tem que retomar um pouco do conteúdo das outras disciplinas para puder situar o aluno, porque ele sozinho não consegue fazer isso. [...] essa são algumas das dificuldades maiores que a gente tem com relação a essa questão da prática, é justamente essa defasagem na formação do aluno e nós teríamos que pensar de que maneira se poderia estar trabalhando de forma interdisciplinar com as 
outras áreas para que certos conteúdos não fossem repetidos e dar maior consistência ao desenvolvimento do currículo. [...] A interdisciplinaridade dos diversos conteúdos e que se tentou já no curso de pedagogia foi quando se pensou nos blocos de estudos ne que os professores estariam avaliando cada bloco de estudos e isso seria um salto de qualidade do curso, que se estaria vendo quais as dificuldades nas diferentes disciplinas, que conteúdos estariam sendo trabalhados, que estratégias estariam sendo em cada uma dessas disciplinas e isso daria um salto de qualidade muito grande porque os professores estariam discutindo as dificuldades que os alunos enfrentam, a dificuldade que ele tem em relação aos conteúdos e em que cada disciplina estaria dando a sua contribuição. (Extraído da etapa de pós-intervenção realizada com Dina)

É possível perceber na colocação da professora que muito ainda tem para ser feito, no sentido de buscar esta inter-relação no contexto das práticas formativas, e que, a partir da possibilidade de se trabalhar conjuntamente, como as partícipes colocaram, abre-se um espaço que, certamente, se for plenamente utilizado, configura-se na possibilidade de inovação no processo formativo, desenvolvido no Curso de Pedagogia da UFPI.

\section{CONSIDERAÇÕES FINAIS}

Ao retomar o ponto inicial desta pesquisa cuja proposta foi estudar a trama que envolve o cotidiano da sala de aula compreendemos ali tratar-se do lugar em que há uma reunião de seres pensantes que compartilham ideias, trocam experiências, contam histórias, enfrentam desafios, rompem com o velho, buscam o novo, enfim, há pessoas que trazem e carregam consigo saberes cotidianos que foram internalizados durante sua trajetória de vida, saberes esses que precisam ser rompidos para dar lugar a novos saberes. O aluno precisa se apropriar das informações que circulam nos meios sociais e culturais para transformá-las em conhecimento. Não podemos perder de vista que essas informações deveriam fazer sentido para a vida do sujeito, para que ele possa ser articulado com suas ações, seus objetivos, seus sonhos e outras aspirações que porventura venha ter.

Pensamos ser necessário que o profissional da educação esteja em constante formação, pois é ele e seu aluno que ocupam o espaço da sala 
de aula, são eles que lidam cotidianamente com a dinâmica do aprender/ensinar e com todos os seus atravessamentos. A afirmação de Vasconcelos (2003) enfatiza que o professor para atuar verdadeiramente como tal, deve considerar sempre a realidade da sala de aula sabendo que é com os alunos que ali estão que ele terá que trabalhar e, além disso, que a escola e o país são aqueles elementos que terá que considerar.

Convém lembrar que na sala de aula nos deparamos com todas essas questões, visto que é o lugar, instituído pela sociedade, para a concretização das aprendizagens, lugar de encontro de pessoas que carregam no seu íntimo quase todas essas características já citadas. Assim, para lidar com todas essas dimensões consideramos ser essencial despertar o desejo de quem aprende e também de quem ensina, pois é o desejo que impulsiona os seres humanos a se movimentarem no mundo.

Dessa maneira, entendemos que sendo a educação intencional e sistemática, que interage com a realidade, com o social e o cultural, deveria encontrar meios de despertar o desejo para o processo de construção do conhecimento. Acreditamos que uma das formas seria investir no conhecimento, no estudo dos problemas da realidade e da condição humana, a fim de capacitar os sujeitos para que esses possam em posterior momento, promoverem suas intervenções.

\section{REFERÊNCIAS}

ARROYO, M. G. Ofício de mestre: imagens e auto imagens. Petrópolis-RJ: Vozes, 2000.

CAVACO, M. H. O ofício do professor: o tempo e as mudanças. In: NÓVOA, A. (Org.). Profissão professor. Portugal: Porto, 1993. p. 155-191.

CATANI, D. B.; SOUSA, C. P. de; VICENTINI, P. P.; SILVA, V. B. O que eu sei de mim narrativas autobiográficas, história da educação e procedimentos de formação. In: Educação e Linguagem, São Bernardo do Campo: UNESP, ano 8, n. 11, p. 31-50, jan./jun. 2005.

CERTEAU, M.; GIARD, L.; MAYOL P. A invenção do cotidiano: 2. Morar, cozinhar. Petrópolis, Rio de Janeiro: Vozes, 2008.

CONTRERAS, J. Autonomia de professores. São Paulo: Cortez, 2002. 
DEPRESBITERIS, L. A avaliação na educação básica: ampliando a discussão. In: Estudos em Avaliação Educacional, no 24, juldez/2001

FIORENTINI, D.; SOUZA JÚNIOR, A. J. de; MELO, G. F. A. de. Saberes Docentes: um desafio para acadêmicos e práticos. In: GERALDI, C. M. G. Cartografias do trabalho docente: professor (a) pesquisador (a). Campinas-SP: Mercado das Letras, 2003. p. 307-335.

IBIAPINA, I. M. L. de M. A prática pedagógica como componente profissionalizante da formação de professores. Texto trabalhado na disciplina Prática pedagógica na escola V. Teresina, 2005. (Mimeo).

IBIAPINA, I. M. L. de M. Reflexividade: estratégias de formação de professores. Texto trabalhado na disciplina Prática pedagógica na escola V. Teresina, 2005. (Mimeo).

IBIAPINA, I. M. L. de M. Docência universitária: um romance construído na reflexão dialógica. 2004. Tese (Doutorado) - UFRN, Natal-RN.

MASETTO, M. T.; ABREU, M. C. de. O professor universitário em Aula - M.G. Ed. S.P.11a.ed.1999

MEIRIEU, P. Carta a um jovem professor. Porto Alegre: Artmed, 2006.

PAIVA, M. M. de F. M. Observação colaborativa: um caminho para a renovação das práticas supervisivas no contexto da formação inicial de professores. In: XII Colóquio da AFIRSE. Section Portugaise: a formação de professores à Luz da investigação. Lisboa, 2002. v. 1.

PONCE, B. J. A aula como instrumento de transformação social. São Paulo, 1989. Dissertação (Mestrado em Educação). PUCSP.

PIMENTA, S. G. Formação de professores: identidade e saberes da docência. IN: PIMENTA, S. G. (Org.). Saberes pedagógicos e atividade docente. São Paulo: Cortez, 1999.

TARDIF, M. Saberes docentes e formação profissional. Petrópolis-RJ: Vozes, 2002

TARDIF, M.; LESSARD, C.; LAHAIE, L. Os professores face ao saber: um esboço de uma problemática do saber docente. In: Teoria da educação: Porto Alegre, n. 4, 1991.

THERRIEN, J. O saber do trabalho docente e a formação do professor. IN: NETO, A. S.; MACIEL, L. S. B. (org.). Reflexões sobre a formação de professores. Campinas: Papirus, 2002. P. 103-114

VASCONCELLOS, C. dos S. Para onde vai o professor? Resgate do professor como sujeito e transformação. São Paulo: Libertad. 2003 
VILLAS BOAS, B. M.a de F. O projeto pedagógico e a avaliação. In: Bases Pedagógicas do Trabalho Escolar II, Mod. III vol. 1. Eixo Integrador: Educação e Trabalho. Brasília: UnB, (2002).

VYGOTSKY, L. S. A construção do pensamento e da linguagem. São Paulo: Martins Fontes, 2000.

Recebido em: 22 de julho de 2018 Aprovado em: 30 de outubro de 2018 